\title{
Prevalence of Depression among Patients with Chronic Painful Physical Condition and Its Association with Quality of Life
}

\author{
Vrushika B. Kanthariya', Keni B. Patel ${ }^{2}$, Mitali H. Patel ${ }^{3}$, Priyanka S. Patel ${ }^{4}$, \\ Dharti N. Hingarajia ${ }^{5}$
}

${ }^{1}$ MPT Student, Ashok and Rita Patel Institute of Physiotherapy, Charotar University of Science and Technology, Changa, Dist: Anand, Gujarat, India.

${ }^{2}$ Clinical Physiotherapist, V4U Multispeciality Hospital, Surat, Gujarat, India

${ }^{3}$ Consultant Physiotherapist, First Physio Rehabilitation \& Fitness Clinic, Surat, Gujarat, India.

${ }^{4}$ Clinical Physiotherapist, First Physio Rehabilitation \& Fitness Centre, Surat, India.

${ }^{5}$ Sr. Lecturer, SPB Physiotherapy College, Veer Narmad South Gujarat University, Surat, Gujarat, India

Corresponding Author: Dharti N. Hingarajia

\begin{abstract}
Background \& Purpose: Some studies have reported associations between depression and pain syndrome. An epidemiological study in the UK reported that $16.9 \%$ of participants with chronic widespread pain also had a psychiatric diagnosis. Purpose of the present study is to know the prevalence of depression among Patients with Chronic Painful Physical condition \& to find out association between depression \& quality of life among patients with chronic painful physical condition.

Methodology: 120 patients with chronic painful physical condition who met inclusion criteria were recruited from SPB Physiotherapy OPD. Written informed consent was taken. All the participants were asked to fill up the Beck's depression inventory (BDI) to determine the prevalence of Depression and the 36-item short form health survey (SF-36) for quality of life assessment.

Results: Among 120 participants $63(52.5 \%)$ participants were reported mild to moderate depression. Result of spearman's test suggested moderate negative correlation $(r=-0.41, P=0.00943)$ between depression and quality of life among participants with Chronic Painful Physical Condition

Conclusion: The present study concluded that $52.5 \%$ patients with chronic painful physical condition have mild to moderate symptoms of depression and there is moderate negative co-relation exist between depression and quality of life among them.
\end{abstract}

Key Words: Depression, Painful Physical Condition, SF36, BDI, Quality of Life

\section{INTRODUCTION}

DEPRESSION is a major public health issue due to its prevalence, high mortality rates ${ }^{[1]}$, suicide risk ${ }^{[2]}$, and economic impact on the society ${ }^{[3]}$. It is considered to be the major cause of years lived with disability (YLD) and is expected to be among the two main causes of disability adjusted years (DALYs) together with ischemic heart disease [4]. The functional limitations caused by depression are equal to or even sometimes greater than the ones engendered by many other chronic medical conditions ${ }^{[5]}$. In spite of the great advances achieved in treatment of depression during the last decades, between 20 and $30 \%$ of cases are not adequately solved by first agent treatments (also known as treatment- resistant depression in literature) ${ }^{[6]}$.

World Health Organization (WHO) has reported that about 450 million people 
worldwide suffer from mental illness and one in four people meets criteria of mental illness at some point in their life ${ }^{[7]}$. Depression disorder presents with depressed mood, loss of interest or pleasure, decreased energy, feelings of guilt or low self-worth, disturbed sleep or appetite, poor concentration, problem of thinking and making decisions, and, in severe stages, recurring thoughts of death or suicide ${ }^{[8]}$.

Depending on the number and severity of symptoms, a depressive episode can be categorized as mild, moderate, or severe. An individual with a mild depressive episode will have some difficulties in continuing with ordinary work and social activities but will probably not cease to function completely. On the other hand, it is very unlikely that the individual with severe depressive episode will be able to continue with social, work, or domestic activities, except to a very limited extent. As for moderate depression, the individual would normally have more than the five symptoms that are needed to make the diagnosis of depression. Moderate episodes have a severity that is intermediate between mild and severe depressions ${ }^{[9]}$.

Depression has many possible causes, including mood disturbance, genetic vulnerability, chronic stressful life, use of psychoactive substances, and medical problems. It is believed that several of these forces interact to bring depression ${ }^{[8,9]}$. Areas in the brain that are affected in cases of depression are the prefrontal cortex, cingulated gyrus, amygdala, hippocampus, thalamus, and hypothalamus. These brain regions are involved in the regulation of motivation, eating, sleeping, energy level, circadian rhythm, and responses to rewarding and aversive stimuli, which are all abnormal in depressed people ${ }^{[10]}$.

Neurotransmitters that are depleted in patients with depression are serotonin that helps regulate sleep, appetite, and mood and inhibits pain. Reduced serotonin secretion is recorded in patients with depression ${ }^{[11]}$. Norepinephrine triggers anxiety and is involved in some types of depression. It determines motivation and reward. Norepinephrine and serotonin (5-HT) modulate subcortical and cortical functions that their shortage in states of depression and anxiety contributes to abnormalities in sleep, concentration, attention and memory, arousal states, appetite, and libido ${ }^{[12]}$. Furthermore, their modulation of the cortical-hippocampal amygdala pathways regulates responses to aversive, stressful, and fearful experience along with modulation of the affective aspects of memory ${ }^{[13]}$.

Some studies have reported associations between depression and a number of long-term medical conditions, including pain syndrome ${ }^{[14-16]}$. An epidemiological study in the United Kingdom reported that $16.9 \%$ of participants with chronic widespread pain also had a psychiatric diagnosis ${ }^{[17]}$. A 7year longitudinal study reported that the presence of multiple physical symptoms is predictive of a new onset of depression, and, conversely, subjects with depression are 3 to 7 times more likely to develop multiple physical symptoms than are subjects who are not depressed ${ }^{[15]}$

More recently, a 1-year longitudinal study reported that no depressed subjects with a long-term medical condition (e.g., migraine, headaches, sinusitis, or back problems) were twice as likely to develop major depression within the next year as were subjects without a long-term medical condition ${ }^{[16]}$. Surprisingly, few studies have attempted to determine if a comorbid medical condition in individuals with chronic painful physical conditions increased the likelihood of having major depressive disorder. Similarly, few studies have attempted to determine the role of obesity, a factor found to be associated with increased pain severity ${ }^{[18]}$ and major depressive disorder, ${ }^{[19]}$ in the association between pain and depression. Some studies have reported associations between depression and a number of long-term medical conditions, including pain syndrome ${ }^{[14-16]}$. 
In the literature there is unclear evidence about prevalence of depression among Patients with Chronic Painful Physical condition \& its association with quality of life \& so present study was conducted to know the Prevalence of Depression and to find out association between depression \& quality of life among patient with chronic painful physical condition.

\section{AIMS AND OBJECTIVES}

1. To know the Prevalence of Depression among patient with chronic painful physical condition.

2. To find out association between depression \& quality of life among patient with chronic painful physical condition.

\section{HYPOTHESIS}

Null Hypothesis H0: There is no association between depression and quality of life among the patients with chronic painful physical condition.

Alternative Hypothesis H1: There is association between depression and quality of life among the patients with chronic painful physical condition.

\section{MATERIALS \& METHODOLOGY}

- Research design: Cross Sectional Study

- Population: Patients with any Chronic Painful Physical condition

- Sampling Technique: Purposive

- Study Duration: 6 months

- Sample size: 120

- Setting: SPB Physiotherapy College

- Outcome measure:

1. Beck's Depression Inventory $(\mathrm{BDI})^{20}$

2. 36-item short form health survey (SF $36)^{21}$

- Inclusion criteria:

1. Subjects with painful physical condition $>6$ months.

2. Subjects attending SPB Physiotherapy College OPD for painful physical condition.
3. Patients willing to participate.

\section{- Exclusion criteria:}

1. Subjects with Acute/Subacute Painful physical Conditions

2. Subjects with traumatic/operative Painful Physical Conditions

3. Subjects on psychiatric/ psychologist/behavioral treatment or medications

4. Subjects with known Neurological/ Cardiopulmonary or any other systemic pathological diseases

Procedure: Participants were explained the procedure and informed consent obtained. We conducted a cross sectional survey of a 40 patients recruited from SPB Physiotherapy OPD completed the 36-item short form health survey (SF-36) and the Beck's depression inventory (BDI). The score is the measure of the level of depression, was calculated from data on use of prescription medication and treatment over a six-month period. SF-36 and BDI these two scales were used to determine the Prevalence of Depression among Patients with Chronic Painful Physical condition \& its association with quality of life.

Flow diagram: Participants recruitment and retention through the study.

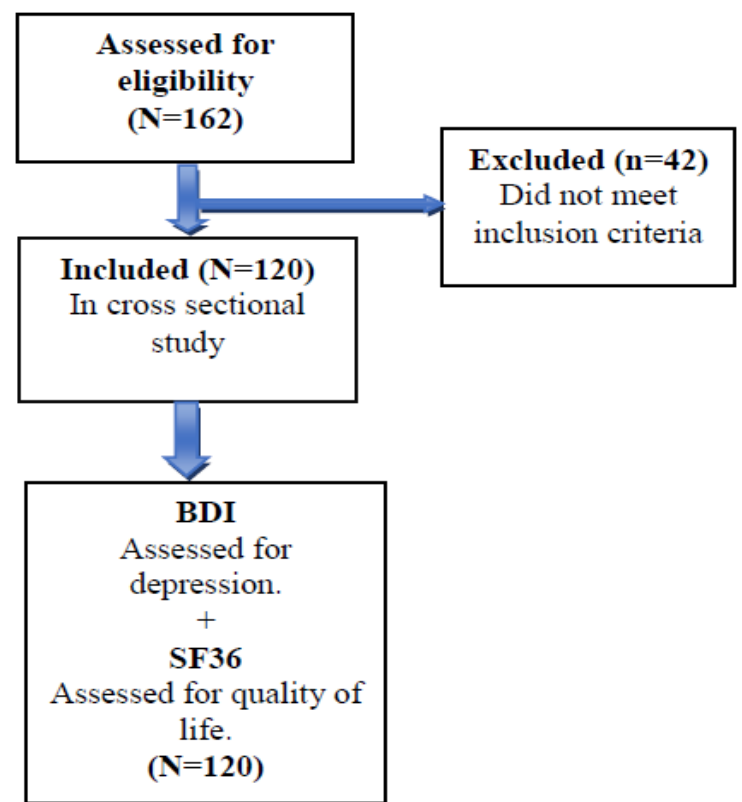


Vrushika B. Kanthariya et.al. Prevalence of depression among patients with chronic painful physical condition and its association with quality of life.

\section{DATA ANALYSIS AND RESULTS}

Statistical analysis was done using SPSS 15version. This study included age, duration of chronic painful physical conditions, BMI, BDI and SF36 as quantitative variables.

Kolmogorov-Smirnov test was applied to check the normality of the data. All quantitative data of this study did not follow the normality. So, non-parametric tests were used for the analysis.

Descriptive statistics were applied for all the quantitative parameters. Spearman's rank correlation analyses were done to determine the association between score on the SF-36 and scores on BDI. Confidence interval kept $95 \%$ and level of significance for all statistical data was set at $\alpha=0.05$.

Total 162 participants were assessed for eligibility among them 42 participants were excluded as they did not meet inclusion criteria. 120 participants were enrolled in study and assessed for BDI and SF36. Mean age of all participants was $55.075 \pm 14.244$. Among 120 participants $78 \%(\mathrm{n}=93)$ were females and $22 \%(\mathrm{n}=27)$ were males. Mean of BMI was $27.042 \pm$ 6.451. Among 120 participants 54 participants had pain from 6-12 months, 36 participants had pain from 1-2 years and 30 participants had pain from more than 2 years.
TABLE-1. THE BASIC CHARACTERISTICS OF DISTRIBUTION.

\begin{tabular}{|l|l|}
\hline $\mathbf{N}=\mathbf{4 0}$ & $55.075 \pm 14.25$ \\
\hline Avg age \pm SD, $\mathrm{y}$ & $27.04 \pm 6.45$ \\
\hline Avg BMI \pm SD, $\mathrm{kg} / \mathrm{m}^{2}$ & $22 \%(27)$ \\
\hline GENDER, \% (NO.) & $78 \%(93)$ \\
\hline Men & $20 \%(24)$ \\
\hline Women & $27.5 \%(33)$ \\
\hline CONDITION,\%(NO.) & $35 \%(42)$ \\
\hline Knee pain & $17.5 \%(21)$ \\
\hline Shoulder pain &
\end{tabular}

Among 120 participants 24 participants had knee pain, 33 participants had shoulder pain, 42 participants had low back pain and 21 participants had more than one conditions.

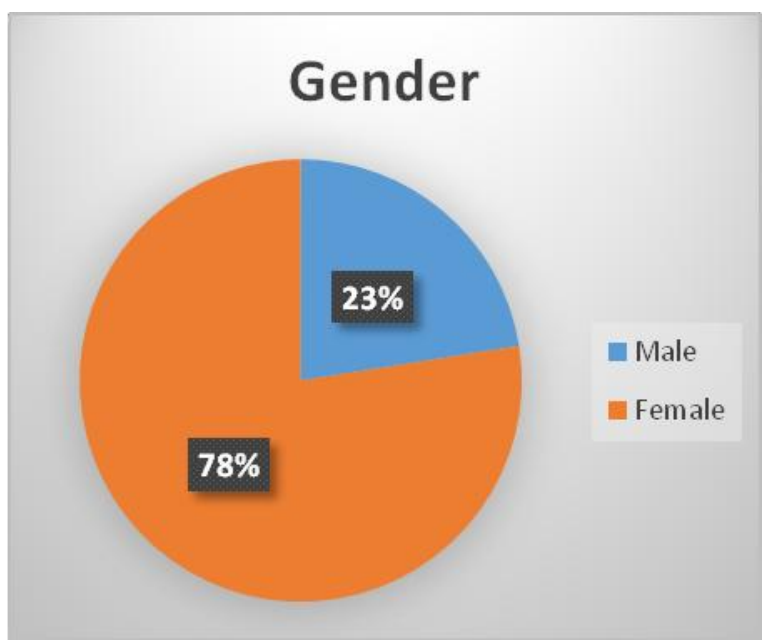

FIGURE-1. GENDER DISTRIBUTION OF SUBJECTS

This graph suggests 22\% Male and $78 \%$ Female participants in this study. According to this distribution female participants were more than male participants in this study.

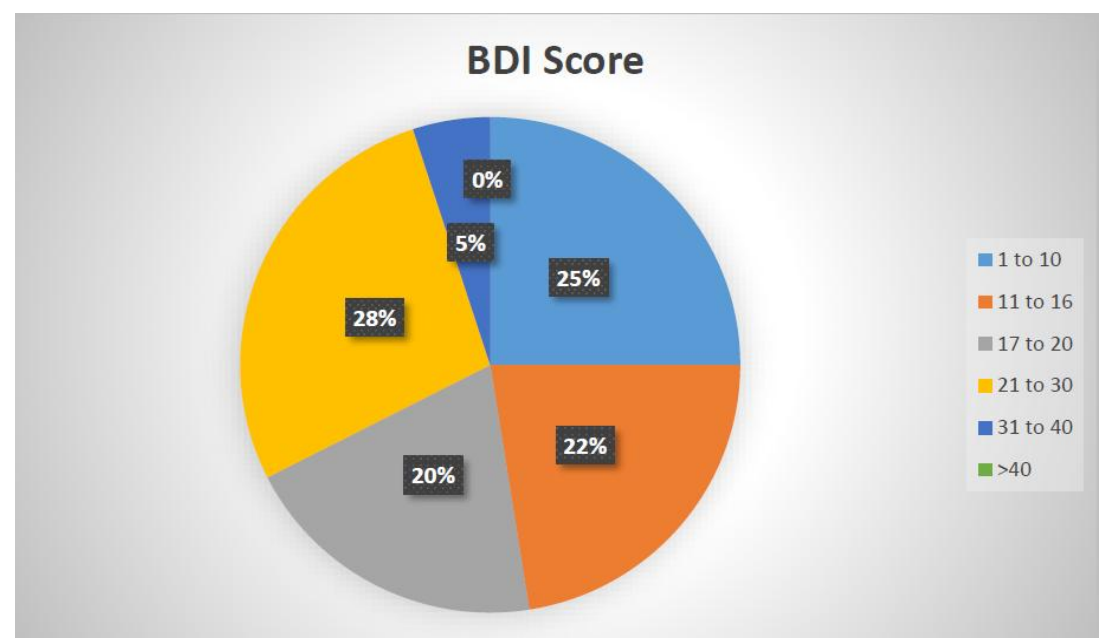

FIGURE-2. BDI SCORING OF SUBJECT 
This graph suggests percentage of BDI scoring of subjects. Among 120 participants $30(24 \%)$ had scoring between 1-10 (this ups and down considered normal), 27 (22\%) had scoring between 1116 (mild mood disturbance), 24 (20\%) had scoring between 17-20 (borderline clinical depression), 33 (27\%) had scoring between 21-30 (moderate depression), 6 (5\%) had scoring between 31-40 (severe depression) and no participants $(0 \%)$ had scoring $>40$ (extreme depression). According to this data depression is present more or less among all the participants while none of the participant was suffering from extreme depression. Total $57(47.5 \%)$ participants had subclinical depression while $63(52.5 \%)$ participants had presence of clinical depression.

TABLE-2. PREVALENCE OF DEPRESSION AMONG PARTICIPANTS ACCORDING TO BDI SCORING

\begin{tabular}{|l|l|l|}
\hline BDI Score & $\mathbf{N}(\%)$ & \\
\hline $1-10$ (this ups and down considered normal) & $30(25 \%)$ & $57(47.5 \%)$ \\
\cline { 1 - 2 } $11-16$ (mild mood disturbance) & $27(22.5 \%)$ & Subclinical Depression \\
\hline $17-20$ (borderline clinical depression) & $24(20 \%)$ & $63(52.5 \%)$ \\
\cline { 1 - 2 } Clinical Depression \\
\cline { 1 - 2 } $31-40$ (moderate depression) & $33(28 \%)$ & \\
\cline { 1 - 2 }$>40$ (extreme depression) & $6(5 \%)$ & \\
\hline
\end{tabular}

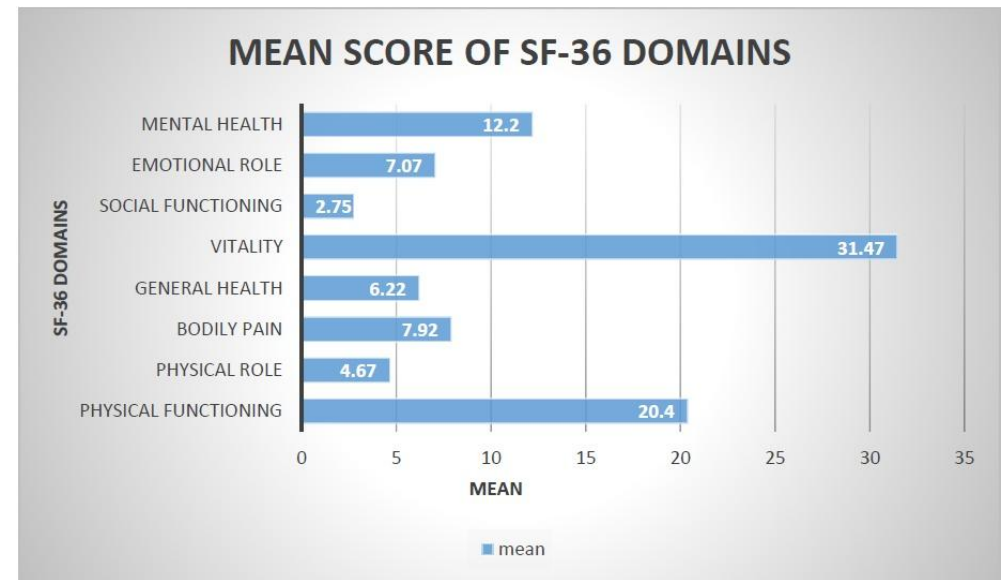

FIGURE-3. QUALITY OF LIFE AMONG PARTICIPANT ACCORDING TO SF-36 SCORING

According to graph mean \pm SD of Physical functioning was $20.4 \pm 4.33$ out of 30 which suggest $68 \%$ disability, Physical role was $4.67 \pm 1.19$ out of 8 which suggest $58.37 \%$ disability. Bodily pain was $7.92 \pm 2.05$ out of 11 which suggest $72.04 \%$ disability. General health was $6.22 \pm 1.33$ out of 10 which suggest $62.25 \%$ disability. Vitality was $31.47 \pm 5.19$ out of 54 which suggest $58.28 \%$ disability. Social functioning was $2.75 \pm 1.13$ out of 3 which suggest $55 \%$ disability. Emotional role was $7.07 \pm 1.48$ out of 11 which suggest $64.31 \%$ disability. Mental health was $12.2 \pm 2.05$ out of 20 which suggest $61 \%$ disability. In these, social functioning is more affected.

For the examination of quality of life SF-36 was used. Mean score of SF-36 of all participants was $92.45 \pm 8.916$ which indicates moderate disability in this population. Components wise Mean and Standard Deviation of all the components of SF-36 are mentioned in following table-3.

TABLE-3. QUALITY OF LIFE AMONG PARTICIPANTS ACCORDING TO SF-36 SCORING

\begin{tabular}{|l|l|l|}
\hline SF-36 Domains & Mean \pm SD & \% QoL \\
\hline Physical functioning & $20.4 \pm 4.33$ & $68 \%$ \\
\hline Physical role & $4.67 \pm 1.19$ & $58.37 \%$ \\
\hline Bodily pain & $7.92 \pm 2.05$ & $72.04 \%$ \\
\hline General health & $6.22 \pm 1.33$ & $62.25 \%$ \\
\hline Vitality & $31.47 \pm 5.19$ & $58.28 \%$ \\
\hline Social functioning & $2.75 \pm 1.13$ & $55 \%$ \\
\hline Emotional role & $7.07 \pm 1.48$ & $64.31 \%$ \\
\hline Mental health & $12.20 \pm 2.05$ & $61 \%$ \\
\hline Total SF36 Score & $92.45 \pm 9.03$ & $62.05 \%$ \\
\hline
\end{tabular}

Spearmen's rank test was used to find out the association between depression assessed by BDI scale and quality of life assessed by SF36 scale. Result of this test suggest moderate negative correlation $\left(r_{\mathrm{s}}=-\right.$ $0.41, \mathrm{P}=0.00943$ ) between depression and 
quality of life among participants with Chronic Painful Physical Condition. P value is analysed and that is $<0.05$ so we are accepting the alternative hypothesis i.e.
There is association (negative) between depression and quality of life among the patients with chronic painful physical condition.

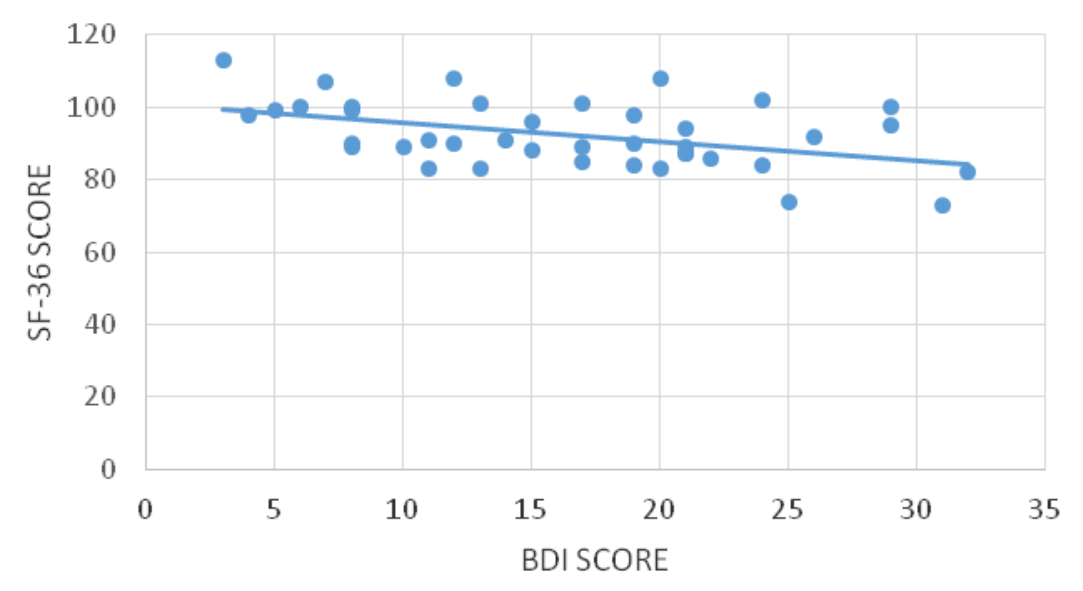

FIGURE-4. ASSOCIATION OF DEPRESSION AND QUALITY OF LIFE ASSESSED WITH SPEARMEN'S RANK TEST

\section{DISCUSSION}

The study was carried out to find out prevalence of depression among the patients with chronic physical painful condition and its association with quality of life. In this study total 120 participants were included who were suffering from Chronic painful physical condition. The main finding was that BDI total score had subclinical mean values in the whole sample, whereas participants with scores $>17$ were found across different patients with Chronic painful physical condition.

Out of 120 participants, 63 participants were categorised from borderline clinical depression to severe depression. Among that 120 participants, 24 participants scored between 17-20 that is categorised under Borderline Clinical Depression, 33 participants scored between 21-30 that is categorised under Moderate Depression, 6 participants scored between 31-40 that is categorised under Severe Depression and none of participants scored above 40 that is categorised under Extreme Depression. Out of 120 participants, 54 participants had pain since 6-12 months, 36 participants had pain since1-2 years and 30 participants had pain more than 2 years. Out of 120 participants, 24 participants had knee pain, 33 participants had shoulder pain, 42 participants had low back pain and 21 participants had more than one condition.

There is evidence of depression in the diagnoses included in the present study. Although BDI scores $<17$ points in the sample indicated subclinical values according to previously established severity levels ${ }^{[22]}$, it should be noted that a percentage of participants from the present sample had BDI values $>17$. In this regard, $52.5 \%$ participants were suffering from depression.

There were 120 participants assessed for SF-36 scale in which Physical functioning suggested $68 \%$ disability, Physical role suggested $58.37 \%$ disability, Bodily pain suggested $72.04 \%$ disability, General health suggested $62.25 \%$ disability, Vitality suggested $58.28 \%$ disability, Social functioning suggested $55 \%$ disability, Emotional role suggested $64.31 \%$ disability and Mental health suggested $61 \%$ disability.

Result of spearmen's test suggest moderate negative correlation $\left(\mathrm{r}_{\mathrm{s}}=-0.41, \mathrm{P}=\right.$ 0.00943 ) between depression and quality of life among participants with Chronic Painful Physical Condition. That means as severity of depression is increasing quality of life is deteriorating in this population. Which 
suggest proper management of depression is necessary to improve quality of life.

In light of these results, there are subgroups of participants with and without significant depression symptoms within participants with the same musculoskeletal diagnosis. Patients with significant depression symptoms are likely to have poorer response to local treatment in cases of LBP ${ }^{[23]}$, chronic whiplash ${ }^{[24]}$ or shoulder pain ${ }^{[25]}$. This is in line with research proposing diagnoses based on depression instead of, or in addition to, the musculoskeletal condition itself [26]. Regarding LBP, symptoms of depression have been proposed as a possible moderator of therapeutic effects ${ }^{[23]}$

For these reasons, depression has recently been proposed as a new diagnosis label that allows patient treatment to be redirected from traditional local therapies (such as electrotherapy, exercise, or surgery) to targeting lifestyle factors (including illness beliefs, stress, sleep, physical activity, and diet) ${ }^{[27]}$. For example, interventions such as pain neuroscience education (PNE) are effective in patients with chronic diseases such as spinal pain, regardless of depression ${ }^{[28]}$. However, PNE combined with cognition targeted motor control training has significantly superior effects, lowering depression symptoms compared with current best-evidence physiotherapy for individuals with chronic spinal pain ${ }^{[28]}$. Moreover, a "McKenzie exercise program" has been shown to be more effective in reducing depression than conventional physiotherapy in patients with chronic nonspecific LBP ${ }^{[29]}$. Therefore, under the same diagnoses as LBP, patients may be stratified clinically as experiencing predominantly depression pain or not in order to direct treatment ${ }^{[30,31]}$

In the present sample, the most frequent diagnosis labels were as Low back pain $(35 \%)$, shoulder pain $(27.5 \%)$, knee pain $(20 \%)$, and patient with more than one condition (17.5\%); The high prevalence rate of depression, along with Chronic Painful Physical Condition, are in line with research suggesting that psychiatric factors play an important role in both chronic pain ${ }^{[32]}$ and the prevalence of comorbid psychiatric disorders in this population ${ }^{[33]}$. Specifically, psychological distress contributes to the variance of depression in chronic pain patients ${ }^{[34]}$. Hence, current musculoskeletal models of care highlight the importance of behaviour change assessments and interventions for success in treatment ${ }^{[35]}$, as well as targeting other lifestyle variables such as sleep disturbance under chronic pain [36], including patients with depression. It is important for clinicians to assess the significance of depression related symptoms under persistent pain conditions. ${ }^{[37]}$

\section{Limitation and Future Scope of the Study Limitation:}

- Sample size was small.

- Male to female ratio was not balanced.

- Study was done only in one OPD.

\section{Future suggestions:}

- The study can be done by large sample size.

- The study can be done with equal male to female ratio.

- The study can be done in several OPDs.

\section{CONCLUSION}

The present study concluded that $52.5 \%$ patients with chronic painful physical condition have mild to moderate symptoms of depression and there is moderate negative co-relation exist between depression and quality of life among them.

\section{Acknowledgement: None}

\section{Conflict of Interest: None}

\section{Source of Funding: None}

\section{Ethical Approval: Approved}

\section{REFERENCES}

1. P. Cuijpers and R.A. Schoevers, "Increased mortality in depressive disorders: a review," 
Current Psychiatry Reports, vol. 6, no. 6, pp. 430-437, 2004.

2. World Health Organization, "World suicide prevention day," 2012, http://www.who.int/mental health/prevention/en/.

3. P. Sobocki, B. Jönsson, J. Angst, and C. Rehnberg, "Cost of depression in Europe," Journal of Mental Health Policy and Economics, vol. 9, no. 2, pp. 87-98, 2006.

4. T.B.Ustu "̈,J.L.Ayuso-Mateos, S.Chatterji, C.Mathers, andC. J. L. Murray, "Global burden of depressive disorders in the year 2000," British Journal of Psychiatry, vol. 184, pp. 386-392, 2004.

5. K. B. Wella, A. Stewart, R. D. Hays et al., "The functioning and well-being of depressed patients. Results from the medical outcomes study," Journal of the American Medical Association, vol. 262, no. 7, pp. 914-919, 1989.

6. NCCMH, Depression: The Treatment and Management of Depression in Adults, NICE Clinical Guidelines, No. 90.

7. World Health Organization, Promoting Mental Health: Concepts Emerging Evidence Practice, Summary Report, World Health Organization, Geneva, Switzerland, 2004.

8. M. Marcus, M. T. Yasamy, M. van Ommeren, D. Chisholm, and S. Saxena, "Depression: a global public health concern," in Proceedings of the 65th World Health Assembly, World Health Organization, Geneva, Switzerland, May 2012, http://www.who.int/ mediacentre /events /2012 /wha65 /journal/.

9. World Health Organization, The Global Burden of Disease 2004 Update, 2008, http://www.who.int/healthinfo/globalburden disease/GBD report 2004update full.pdf.

10. E. J.Nestler,M. Barrot, R. J. DiLeone, A. J. Eisch, S. J. Gold, and L. M. Monteggia, "The neurobiology of depression," Neuron, vol. 34, no. 1, pp. 13-25, 2002.

11. M. J. Owens and C. B. Nemeroff, "Role of serotonin in the pathophysiology of depression," Clinical Chemistry, vol. 40, no. 2, pp. 288-295, 1994.

12. D. S. Charney, "Monoamine dysfunction and the pathophysiology and treatment of depression," Journal of Clinical Psychiatry, vol. 59, supplement 14, pp. 11-14, 1998.

13. K. J. Ressler and C. B.Nemeroff, "Role of serotonergic and noradrenergic systems in the pathophysiology of depression and anxiety disorders," Depression and Anxiety, vol. 12, supplement 1, pp. 2-19, 2000.

14. Croft PRPapegeorgiou ACFerry SThomas EJayson MISilman AJ Psychologic distress and low back pain: evidence from a prospective study in the general population. Spine. 1995;202731- 2737.

15. Hotopf MMayou RWadsworth MWessely S Temporal relationships between physical symptoms and psychiatric disorder: results from a national birth cohort. $\mathrm{Br} \mathrm{J}$ Psychiatry. 1998;173255-261.

16. Patten SB Long-term medical conditions and major depression in a Canadian population study at waves 1 and 2 . J Affect Disord. 2001;6335- 41.

17. Benjamin SMorris SMcBeth JMacfarlane GJSilman AJ The association between chronic widespread pain and mental disorder: a population-based study. Arthritis Rheum. 2000;43561- 567.

18. Barofsky IFontaine KRCheskin LJ Pain in the obese: impact on health-related qualityoflife. Ann Behav Med. 1998;19408- 410.

19. Siegel JMYancey AKMcCarthy WJ Overweight and depressive symptoms among African- American women. Prev Med. 2000;31232- 240.

20. Harris, C. A., \& D'Eon, J. L. (2008). Psychometric properties of the Beck Depression Inventory-Second Edition in individuals with chronic pain. Pain, 137(3), 609-622.

21. Beaton D, Hogg-Johnson S, Bombardier C. Evaluating changes in health status: Reliability and responsiveness of five generic health status measures in workers with musculoskeletal disorders. J Clin Epidemiol. 1997. 50; 1:79-93

22. Neblett R, Hartzell MM, Mayer TG, Cohen $\mathrm{H}$, Gatchel RJ. Establishing clinically relevant severity levels for the central sensitization inventory. Pain Pract 2017;17(2):166-75.

23. Aguilar Ferrandiz ME, Nijs J, Gidron Y, et al. Auto-targeted neurostimulation is not superior to placebo in chronic low back pain: A fourfold blind randomized clinical trial. Pain Physician 2016;19(5):E707-19.

24. Jull G, Sterling M, Kenardy J, Beller E. Does the presence of sensory hypersensitivity influence outcomes of physical rehabilitation for chronic whiplash? 
Vrushika B. Kanthariya et.al. Prevalence of depression among patients with chronic painful physical condition and its association with quality of life.

-A preliminary RCT. Pain 2007;129 (1):2834.

25. Gwilym SE, Oag HCL, Tracey I, Carr AJ. Evidence that central sensitisation is present in patients with shoulder impingement syndrome and influences the outcome after surgery. J Bone Joint Surg Br 2011;93(4): 498-502.

26. Williams DA. Phenotypic features of central sensitization. J Appl Biobehav Res. In press.

27. Nijs J, Polli A, Willaert W, Malfliet A, Huysmans E, Coppieters I. Central sensitisation: Another label or useful diagnosis? Drug Ther Bull 2019;57(4):60-3.

28. Malfliet A, Kregel J, Coppieters I, et al. Effect of pain neuroscience education combined with cognition-targeted motor control training on chronic spinal pain: A randomized clinical trial. JAMA Neurol 2018;75(7):808-17.

29. Bid D, Soni N, Yadav A, Rathod P. A study on central sensitization in chronic nonspecific low back pain. Indian J Physiother Occup Ther 2017;11(4):165-75.

30. Nijs J, Clark J, Malfliet A, et al. In the spine or in the brain? Recent advances in pain neuroscience applied in the intervention for low back pain. Clin Exp Rheumatol 2017;35(Suppl 107) (5):108-15.

31. Nijs J, Apeldoorn A, Hallegraeff $H$, et al. Low back pain: Guidelines for the clinical classification of predominant neuropathic, nociceptive, or central sensitization pain. Pain Physician 2015;18(3): E333-46.

32. Workman EA, Hubbard JR, Felker BL. Comorbid psychiatric disorders and predictors of pain management program success in patients with chronic pain. Prim
Care Companion J Clin Psychiatry 2002; 04(04):137-40.

33. Vargas C, Bilbeny N, Balmaceda C, et al. Costs and consequences of chronic pain due to musculoskeletal disorders from a health system perspective in Chile. Pain Rep 2018;3(5): e656.

34. Van Wilgen CP, Vuijk PJ, Kregel J, et al. Psychological distress and widespread pain contribute to the variance of the central sensitization inventory: A cross-sectional study in patients with chronic pain. Pain Pract 2018;18(2):239-46.

35. Briggs AM, Jordan JE, Jennings $M$, et al. Supporting the evaluation and implementation of musculoskeletal models of care: A globally informed framework for judging readiness and success. Arthritis Care Res 2017;69(4):567-77.

36. Nijs J, Mairesse O, Neu D, et al. Sleep disturbances in chronic pain: Neurobiology, assessment, and treatment in physical therapist practice. Phys Ther 2018;98(5): 325-35.

37. Nijs J, Leysen L, Adriaenssens N, et al. Pain following cancer treatment: Guidelines for the clinical classification of predominant neuropathic, nociceptive and central sensitization pain. Acta Oncol 2016;55(6): 659-63

How to cite this article: Kanthariya VB, Patel $\mathrm{KB}$, Patel MH et.al. Prevalence of depression among patients with chronic painful physical condition and its association with quality of life. Int J Health Sci Res. 2021; 11(10): 17-25. DOI: https://doi.org/10.52403/ijhsr.20211004 